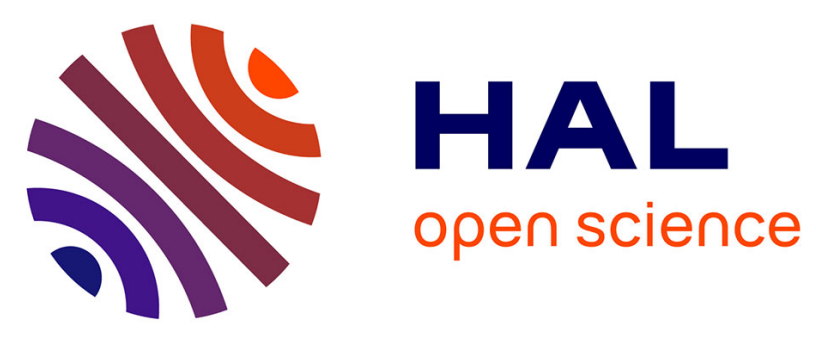

\title{
Oral and oropharyngeal cancer surgery with free-flap reconstruction in the elderly: Factors associated with long-term quality of life, patient needs and concerns. A GETTEC cross-sectional study
}

Alexandre Bozec, Claire Majoufre, Marie de Boutray, Jocelyn Gal, Emmanuel Chamorey, Lise-Marie Roussel, Pierre Philouze, Sylvie Testelin, Marine Coninckx, Christine Bach, et al.

\section{- To cite this version:}

Alexandre Bozec, Claire Majoufre, Marie de Boutray, Jocelyn Gal, Emmanuel Chamorey, et al.. Oral and oropharyngeal cancer surgery with free-flap reconstruction in the elderly: Factors associated with long-term quality of life, patient needs and concerns. A GETTEC cross-sectional study. Surgical Oncology, 2020, 35, pp.81-88. 10.1016/j.suronc.2020.08.014 . hal-03203172

\section{HAL Id: hal-03203172 \\ https://hal.science/hal-03203172}

Submitted on 20 Apr 2021

HAL is a multi-disciplinary open access archive for the deposit and dissemination of scientific research documents, whether they are published or not. The documents may come from teaching and research institutions in France or abroad, or from public or private research centers.
L'archive ouverte pluridisciplinaire HAL, est destinée au dépôt et à la diffusion de documents scientifiques de niveau recherche, publiés ou non, émanant des établissements d'enseignement et de recherche français ou étrangers, des laboratoires publics ou privés. 


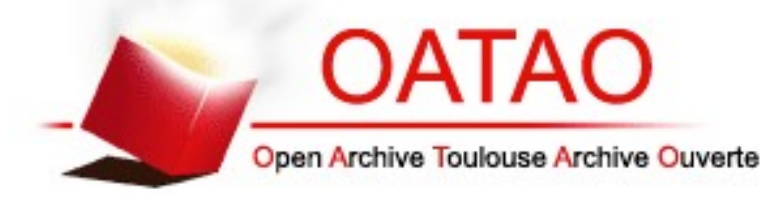

\section{Open Archive Toulouse Archive Ouverte}

OATAO is an open access repository that collects the work of Toulouse researchers and makes it freely available over the web where possible

This is an author's version published in: https://oatao.univ-toulouse.fr/27614

Official URL :

https://doi.org/10.1016/j.suronc.2020.08.014

To cite this version:
Bozec, Alexandre and Majoufre, Claire and De Boutray, Marie [et
al.] Oral and oropharyngeal cancer surgery with free-flap
reconstruction in the elderly: Factors associated with long-term
quality of life, patient needs and concerns. A GETTEC cross-
sectional study. (2020) Surgical Oncology, 35. 81-88. ISSN 0960-
7404

Any correspondence concerning this service should be sent to the repository administrator: tech-oatao@listes-diff.inp-toulouse.fr 


\title{
Oral and oropharyngeal cancer surgery with free-flap reconstruction in the elderly: Factors associated with long-term quality of life, patient needs and concerns. A GETTEC cross-sectional study
}

\author{
Alexandre Bozec $^{\mathrm{a}, *}$, Claire Majoufre ${ }^{\mathrm{b}}$, Marie De Boutray ${ }^{\mathrm{c}}$, Jocelyn Gal ${ }^{\mathrm{d}}$, Emmanuel Chamorey ${ }^{\mathrm{d}}$, \\ Lise-Marie Roussel $^{\mathrm{e}}$, Pierre Philouze ${ }^{\mathrm{f}}$, Sylvie Testelin ${ }^{\mathrm{g}}$, Marine Coninckx ${ }^{\mathrm{h}}$, Christine Bach ${ }^{\mathrm{i}}$, \\ Philippe Schultz ${ }^{j}$, Renaud Garrel ${ }^{\mathrm{k}}$, Marie-Yolande Louis ${ }^{\mathrm{e}}$, Emmanuel Babin ${ }^{1}$, Alain Cosmidis ${ }^{\mathrm{f}}$, \\ Philippe Céruse $^{\mathrm{f}}$, Bertrand Baujat ${ }^{\mathrm{h}}$, Dorian Culié ${ }^{\mathrm{a}}$, Olivier Dassonville ${ }^{\mathrm{a}}$, Gilles Poissonnet ${ }^{\mathrm{a}}$, \\ Grégoire D'Andrea $^{a}$, Joanne Guerlain ${ }^{\mathrm{m}}$, Sébastien Vergez ${ }^{\mathrm{n}}$, Agnès Dupret-Bories ${ }^{\mathrm{n}}$
}

${ }^{\text {a }}$ Face and Neck University Institute, Antoine Lacassagne Centre, Côte d'Azur University, Nice, France

b Department of Oral and Maxillofacial Surgery, Pellegrin Hospital, University Hospital of Bordeaux, France

${ }^{\mathrm{c}}$ Department of Plastic, Maxillofacial, and Oral Surgery, Gui de Chauliac Hospital, University Hospital of Montpellier, France

d Department of Statistics, Antoine Lacassagne Centre, Côte d'Azur University, Nice, France

e Department of Maxillo-Facial and Head and Neck Surgery, François-Baclesse Centre, Caen, France

${ }^{\mathrm{f}}$ Department of Head and Neck Surgery, Lyon Nord Hospital Centre, University Hospital of Lyon, France

${ }^{g}$ Department of Maxillo-Facial Surgery, University Hospital of Amiens-Picardie, France

${ }^{\mathrm{h}}$ Department of Head and Neck Surgery, Tenon Hospital, Public Assistance Hospitals of Paris, France

${ }^{i}$ Department of Head and Neck Surgery, Foch Hospital, Suresnes, France

${ }^{\mathrm{j}}$ Department of Head and Neck Surgery, University Hospital of Strasbourg, France

${ }^{\mathrm{k}}$ Department of Head and Neck Surgery, University Hospital of Montpellier, France

${ }^{1}$ Department of Head and Neck Surgery, University Hospital of Caen, France

${ }^{\mathrm{m}}$ Department of Head and Neck Surgery, Gustave Roussy Institute, Villejuif, France

${ }^{\mathrm{n}}$ University Cancer Institute of Toulouse - Oncopole, Toulouse, France

\section{A R T I C L E I N F O}

\section{Keywords:}

Quality of life

Patient concerns

Elderly patients

Oral cancer

Free-flap reconstruction

\begin{abstract}
A B S T R A C T
Objectives: To assess the factors associated with long-term quality of life (QoL) and patient concerns in elderly oral or oropharyngeal cancer (OOPC) patients after oncologic surgery and free-flap reconstruction.

Methods: Patients aged over 70 years who were still alive and disease-free at least 1 year after surgery were enrolled in this cross-sectional multicentric study. Patients completed the EORTC QLQ-C30, -H\&N35 and -ELD14 QoL questionnaires, and the Hospital Anxiety and Depression Scale (HADS). Patient needs were evaluated using the Patient Concerns Inventory (PCI). Factors associated with these clinical outcomes were determined in univariate and multivariate analysis.

Results: Sixty-four patients were included in this study. Long-term QoL, functioning scales and patient autonomy were well-preserved. Main persistent symptoms were fatigue, constipation and oral function-related disorders. Salivary and mastication/swallowing problems were the main patient concerns. The mean number of patient concerns increased with the deterioration of their QoL. Psychological distress (HADS score $\geq 15$ ) and patient frailty (G8 score < 15) were significantly associated with poor QoL outcomes.

Conclusions: We found a negative correlation between the number of patient concerns and QoL. Dental rehabilitation and psychological and nutritional supportive measures are of critical importance in the multidisciplinary management of elderly OOPC patients.
\end{abstract}

\footnotetext{
* Corresponding author. Institut Universitaire de la Face et du Cou, 31 avenue de Valombrose, 06103, Nice, France.

E-mail address: alexandre.bozec@nice.unicancer.fr (A. Bozec).
} 


\section{Introduction}

Surgery still plays a major role in the management of patients with oral/oropharyngeal cancer (OOPC) [1]. Over the past three decades, microvascular free tissue transfer has become the gold standard in reconstruction of large oral/oropharyngeal oncologic defects [2-4]. With the aging of the population, more than one third of OOPC patients are over 70 years of age [5]. Besides survival outcomes, quality of life (QoL), psychological and social problems represent major issues in this specific patient population. Analyzing patient concerns after major oncologic surgical procedures is mandatory in the hope of improving patient outcomes [6].

The reliability of head and neck free flap reconstruction is now wellestablished, including in the elderly population [7]. However, long-term QoL, psychosocial well-being along with patient concerns have not been properly evaluated in this population.

The aims of this multicentric cross-sectional study were to assess long-term QoL, psychosocial outcomes and patient concerns after OOPC surgery and free-flap reconstruction in the elderly, as well as to determine the clinical factors associated with these patient-reported outcomes.

\section{Material and methods}

This cross-sectional multicentric study was conducted by the GETTEC (Groupe d'Etude des Tumeurs de la Tête et du Cou) study group.

\subsection{Patients}

The inclusion criteria of our study were as follows:

- OOPC surgery with free-flap reconstruction between January 2009 and October 2017, at 10 French tertiary cancer care centers (Nice, Toulouse, Bordeaux, Montpellier, Lyon, Caen, Amiens, Paris, Suresnes and Strasbourg).

- Alive and disease-free patients at least 1 year after surgery.

The exclusion criteria were as follows:

- Patients who were not fluent in French or who could not answer the QoL questionnaires for physical, psychological or other reasons.

- Intercurrent disease (any severe cardiac, respiratory, hepatic, renal or neurological disease) responsible for a potentially significant impact on patient daily life and QoL.

Patients were staged according to the 2009 American Joint Committee on Cancer (AJCC) staging system. Patient vulnerability was evaluated using the G8 (Geriatric 8) health status questionnaire (frailty screening tool) [8].

\subsection{Ethical consideration}

The protocol and all accompanying material provided to patients were reviewed and approved by institutional ethics committees prior to the start of the study. The study was conducted in compliance with the Helsinki Declaration. Informed consent was obtained from each of the participants.

\subsection{QoL evaluation}

Patients completed the French versions of the European Organization for Research and Treatment of Cancer (EORTC) Core QoL Questionnaire (QLQ-C30), the EORTC Head and Neck Cancer module (QLQH\&N35) and the EORTC Elderly cancer patients module (QLQ-ELD14) at the time of our study (November 2018, i.e. at least 1 year after surgery). As recommended by the EORTC, the scales and single item variables of the three questionnaires were transformed linearly into a score from 0 to 100. A high score for a functioning scale and for the global QoL scale represents a better level of functioning, whereas a high score for a symptom scale or a single-item scale denotes a high level of symptoms or problems for the EORTC QLQ-C30 and QLQ-HN35 questionnaires. In the QLQ-ELD14 module, high scores are defined as poor mobility, severe joint stiffness, severe worries about others, severe worries about the future, and high burden of illness, but good family support and good maintenance of autonomy and purpose.

\subsection{Psychosocial outcomes}

Patients completed the French version of the Hospital Anxiety and Depression Scale (HADS) questionnaire at the time of our study. The HADS is widely used to measure anxiety and depression and is considered an effective screening tool to assess psychological distress in cancer patients [9]. It consists of two subscales (HADS-A and HADS-D) that evaluate anxiety and depression, respectively. Scores for each subscale range from 0 to 21 and a cut-off score of 11 is considered to be a good indicator of anxiety or depressive disorders. For the global score, a cut-off score of 15 is recognized to provide a good indicator of anxio-depressive disorders and psychological distress.

To measure more accurately the impact of treatment on daily and social life, we also analyzed patient responses to 2 open questions: "What are the main physical changes impacting your daily life since OOPC surgery?" and: "What are the main changes in your social life since OOPC surgery?"

\subsection{Patient concerns inventory}

The purpose of the patient concerns inventory (PCI) is to allow patients to raise issues that they would like to discuss during their consultation $[10,11]$. Patients were asked: 'If you were to attend a clinical consultation today, which of the following 55 concerns would you wish to discuss with your head and neck cancer consultant/doctor?' The Yes/No options were arranged alphabetically and were not grouped. Furthermore, patients could tick 'Other' and suggest concerns that were not listed. Next, patients were asked: 'If you were to attend a clinical consultation today, which of the following members of staff would you like to see or be referred on to?' There were 14 types of health professional listed and patients could add 'others' not on the list.

\subsection{Swallowing and oral diet}

Since swallowing disorders and modifications of oral diet are among the main persisting problems in OOPC patients undergoing oncologic surgery, we also evaluated the severity of dysphagia and the restriction of oral diet using the Dysphagia Outcome and Severity Scale (DOSS) [12]. This well-standardized 7-step scale is used to classify the severity of dysphagia, with level 7 corresponding to normal swallowing and level 1 to complete enteral feeding.

\subsection{Statistical analyses}

We analyzed the influence on QLQ-C30, QLQ-H\&N35, QLQ-ELD14, HADS and DOSS scores, as well as on the number of PCI concerns raised and the number of staff members selected of the following factors: age ( $<v s>80$ years, at the time of our study), gender, G8 score $(<v s \geq$ 15 ), tumor site (oral cavity $v s$ oropharynx), T-stage ( $<v s \geq 4$ ), N-stage $(<v s \geq 1)$, adjuvant treatment (postoperative radiotherapy: yes $v s$ no), education level ( $<v s \geq$ high school diploma), living alone at home (yes $v s$ no), alcohol consumption (yes $v s$ no), tobacco consumption (yes $v s$ no), and HADS score $(<v s \geq 15)$.

Univariate analyses were performed using Chi-squared tests confirmed by Fisher's exact tests, Student's t tests or Wilcoxon tests, when appropriate. For multivariate analysis (conducted only when more 
than one factor was significant in univariate analyses), all variables associated with $\mathrm{p}<0.05$ on univariate analysis were included in linear regression models with forward stepwise selection.

We looked for a potential correlation between QoL scores and the number of PCI concerns raised and staff members selected using Spearman correlation tests. We considered the correlation between 2 scores when $r \geq 0.40$ or $r \leq-0.40$; the closer the coefficient of correlation to 1 (or -1 ), the stronger the link between both variables.

As previously reported [13], several scales and single-item variables of the EORTC QLQ-C30 and H\&N35 QoL questionnaires were analyzed together to facilitate presentation of the results:

- physical, role, emotional, cognitive and social functioning scales were grouped together to obtain the mean score for functioning scales

- fatigue, nausea and vomiting, pain, dyspnea, insomnia, appetite loss, constipation and diarrhea were grouped together to obtain the mean score for general symptoms

- social contact, social eating, pain, swallowing, senses, speech, sexlife, teeth, open mouth, dry mouth, sticky saliva, cough and feeling ill were grouped together to obtain the mean score for head and neck symptoms.

All statistical analyses were performed at 5\% alpha risk or $95 \%$ confidence interval by the biostatistician using R.3.0.1 software on Windows.

\section{Results}

\subsection{Patients' clinical characteristics}

A total of 64 patients (mean age: $75.4 \pm 4.8$ at the time of surgery and $78.5 \pm 4.6$ at the time of our study) were included in the study. Their main clinical characteristics are shown in Table 1 . The mean time between surgery and QoL assessment was $3.1 \pm 2.8$ years.

\subsection{EORTC QLQ-C30, H\&N35 and ELD14 scores}

The EORTC QLQ-C30, H\&N35 and ELD14 scores obtained by patients are shown in Tables $2-4$.

Factors significantly associated with QoL scores are shown in Table 5. Of note, after uni- and multivariate analysis, a G8 score $<15$ (i. e. frail patient) and a HADS score $\geq 15$ (i.e. anxio-depressive disorders, psychological distress) were associated with poor QoL outcomes (QLQC30 and QLQ-H\&N35 questionnaires). A HADS score $\geq 15$ had a pejorative impact on all QLQ-ELD14 scores.

Table 1

Patients' clinical characteristics.

\begin{tabular}{lll}
\hline Characteristics & $\begin{array}{l}\text { All patients }(\mathrm{n}= \\
64)\end{array}$ & $\begin{array}{l}\text { Percentage } \\
(\%)\end{array}$ \\
\hline Gender: male/female & $38 / 26$ & $60 / 40$ \\
Age: $</>80$ years (at the time of the study) & $38 / 26$ & $60 / 40$ \\
G8 score: $<$ vs $\geq 15$ (at the time of the study) & $31 / 33$ & $49 / 51$ \\
Education level: $\leq />$ high school diploma & $44 / 20$ & $69 / 31$ \\
Living alone at home: yes $v s$ no & $26 / 38$ & $40 / 60$ \\
Alcohol consumption: before/after surgery & $11 / 3$ & $17 / 5$ \\
Tobacco consumption: before/after surgery & $32 / 1$ & $50 / 2$ \\
Tumor site: oral cavity/oropharynx & $48 / 16$ & $75 / 25$ \\
T-Stage: T2/T3/T4 & $14 / 14 / 36$ & $22 / 22 / 56$ \\
N-Stage: N0/N1/N2a-c/N3 & $43 / 8 / 13 / 0$ & $67 / 13 / 20 / 0$ \\
Type of reconstruction: mandible/maxilla/ & $25 / 1 / 38$ & $39 / 2 / 59$ \\
$\quad$ soft tissues & & \\
Adjuvant treatment: None/RT/RT + CT & $14 / 39 / 11$ & $22 / 61 / 17$ \\
\hline
\end{tabular}

G8: Geriatric-8 health status score; RT: radiotherapy; CT: concurrent chemotherapy.
Table 2

EORTC QLQ-C30 scores.

\begin{tabular}{llllll}
\hline Variables & Mean & SD & $\begin{array}{l}\text { Cronbach's } \\
\text { alpha }\end{array}$ & $\begin{array}{l}\text { Lower CI } \\
95 \%\end{array}$ & $\begin{array}{l}\text { Upper CI } \\
95 \%\end{array}$ \\
\hline $\begin{array}{l}\text { Global quality of } \\
\quad \text { life }\end{array}$ & 70.0 & 20.5 & 0.88 & 0.79 & 0.93 \\
$\begin{array}{l}\text { Functioning scales } \\
\text { Physical }\end{array}$ & & & & & \\
$\quad$ functioning & 80.4 & 20.7 & 0.79 & 0.69 & 0.87 \\
Role functioning & 81.8 & 25.6 & 0.75 & & \\
Emotional & 82.7 & 18.7 & 0.77 & 0.47 & 0.88 \\
$\quad$ functioning & & & & & 0.83 \\
Cognitive & 81.8 & 21.3 & 0.62 & 0.36 & 0.83 \\
$\quad$ functioning & & & & & \\
Social functioning & 78.7 & 24.7 & 0.6 & 0.38 & 0.74 \\
$\begin{array}{l}\text { Symptom scales/Items } \\
\text { Fatigue }\end{array}$ & 25.7 & 21.9 & 0.76 & & \\
Nausea/vomiting & 1.8 & 6.7 & 0.71 & 0.62 & 0.85 \\
Pain & 18.2 & 22.1 & 0.74 & 0.5 & 0.82 \\
Dyspnoea & 14.6 & 24.4 & NA & NA & NA \\
Insomnia & 22.4 & 33.1 & NA & NA & NA \\
Appetite loss & 20.3 & 30.0 & NA & NA & NA \\
Constipation & 26.0 & 32.7 & NA & NA & NA \\
Diarrhea & 6.3 & 20.4 & NA & NA & NA \\
Financial & 4.7 & 15.5 & NA & NA & NA \\
$\quad$ difficulties & & & & & \\
\hline
\end{tabular}

SD: standard deviation; CI: confidence interval; NA: not applicable.

A high score for a functioning scale and for the global QoL scale represents a better level of functioning, whereas a high score for a symptom scale or a singleitem scale denotes a high level of symptoms or problems.

Table 3

EORTC QLQ-H\&N35 scores.

\begin{tabular}{lcclll}
\hline Variables & Mean & SD & $\begin{array}{l}\text { Cronbach's } \\
\text { alpha }\end{array}$ & $\begin{array}{l}\text { Lower CI } \\
95 \%\end{array}$ & $\begin{array}{l}\text { Upper CI } \\
95 \%\end{array}$ \\
\hline \multicolumn{2}{l}{ Symptom scales/Items } & & & & \\
Pain & 22.6 & 25.6 & 0.84 & 0.72 & 0.91 \\
Swallowing & 32.1 & 25.1 & 0.74 & 0.6 & 0.84 \\
Senses & 24.7 & 29.6 & 0.66 & 0.36 & 0.83 \\
Speech & 25.5 & 23.4 & 0.63 & 0.37 & 0.78 \\
Social eating & 42.1 & 33.8 & 0.88 & 0.8 & 0.93 \\
Social contact & 16.9 & 20.5 & 0.81 & 0.72 & 0.89 \\
Sexuality & 47.9 & 42.5 & 0.92 & 0.8 & 0.98 \\
Teeth & 41.2 & 41.7 & NA & NA & NA \\
Mouth & 46.3 & 36.9 & NA & NA & NA \\
$\quad$ opening & & & & & \\
Dry mouth & 50.5 & 40.7 & NA & NA & NA \\
Sticky saliva & 44.2 & 42.4 & NA & NA & NA \\
Coughing & 16.6 & 23.0 & NA & NA & NA \\
Filling ill & 6.7 & 15.9 & NA & NA & NA \\
\hline
\end{tabular}

SD: standard deviation; CI: confidence interval; NA: not applicable.

A high score for a symptom scale or a single-item scale denotes a high level of symptoms or problems.

\subsection{Psychosocial outcomes}

The mean HADS-A score was $5.1 \pm 3.1$ and $4(6 \%)$ patients had a HADS-A score $\geq 11$ suggesting anxiety disorders. The mean HADS-D score was $4.6 \pm 4.1$ and $8(13 \%)$ patients had a HADS-D score $\geq 11$ suggesting depressive problems. The mean global HADS score was $9.7 \pm$ 6.4 and 17 (27\%) patients had a global HADS score $\geq 15$ indicating anxio-depressive disorders and psychological distress.

Patient responses to the open question: "What are the main physical changes impacting your daily life since OOPC surgery?" are presented in Fig. 1. Ten (16\%) patients reported no significant physical changes. The 2 most frequent physical changes reported by patients were: 1 ) oral diet restrictions and swallowing problems; 2) physical appearance. Patient responses to the open question: "What are the main changes in your social life since OOPC surgery?" are presented in Fig. 2. Thirty-nine (61\%) patients reported no significant social changes. The 2 most 
Table 4

EORTC QLQ-ELD14 scores.

\begin{tabular}{llllll}
\hline Variables & Mean & SD & $\begin{array}{l}\text { Cronbach's } \\
\text { alpha }\end{array}$ & $\begin{array}{l}\text { Lower CI } \\
95 \%\end{array}$ & $\begin{array}{l}\text { Upper CI } \\
95 \%\end{array}$ \\
\hline $\begin{array}{l}\text { Scales/Items } \\
\text { Mobility }\end{array}$ & 23.6 & 27.1 & 0.83 & 0.7 & 0.9 \\
$\begin{array}{l}\text { Joint stiffness } \\
\text { Worries about the }\end{array}$ & 30.7 & 31.0 & NA & NA & NA \\
$\quad$ future & 27.4 & 27.1 & 0.83 & 0.7 & 0.91 \\
$\quad \begin{array}{l}\text { Worries about } \\
\quad \text { others }\end{array}$ & 15.6 & 21.1 & 0.55 & 0.27 & 0.8 \\
$\begin{array}{l}\text { Burden of illness } \\
\text { Family support }\end{array}$ & 49.7 & 33.1 & 0.83 & 0.67 & 0.91 \\
$\begin{array}{l}\text { Maintaining } \\
\quad \text { purpose }\end{array}$ & 54.1 & 43.0 & NA & NA & NA \\
\hline
\end{tabular}

SD: standard deviation; CI: confidence interval; NA: not applicable.

High scores denote poor mobility, severe joint stiffness, severe worries about others, severe worries about the future, and high burden of illness, but good family support and good maintenance of autonomy and purpose.

Table 5

Factors significantly associated with patient QoL and clinical outcomes.

\begin{tabular}{|c|c|c|c|}
\hline Variables & $\begin{array}{l}\text { Factors identified } \\
\text { after UA/MA }\end{array}$ & $\begin{array}{l}\text { Mean } \\
\text { scores }\end{array}$ & $\begin{array}{l}\text { P values in } \\
\text { MA }\end{array}$ \\
\hline \multirow[t]{2}{*}{ Global QoL score (QLQ-C30) } & $\mathrm{G} 8:</ \geq 15$ & $\begin{array}{l}58.9 / \\
79.3\end{array}$ & $\mathrm{p}<0.001$ \\
\hline & HADS: $</ \geq 15$ & $\begin{array}{l}77.6 / \\
45.8\end{array}$ & $\mathrm{p}<0.001$ \\
\hline \multirow[t]{2}{*}{$\begin{array}{l}\text { Functioning scales (QLQ- } \\
\text { C30) }\end{array}$} & G8: $</ \geq 15$ & $\begin{array}{l}73.2 / \\
87.0\end{array}$ & $\mathrm{p}=0.001$ \\
\hline & HADS: $</ \geq 15$ & $\begin{array}{l}86.8 / \\
64.3\end{array}$ & $\mathrm{p}<0.001$ \\
\hline \multirow[t]{2}{*}{$\begin{array}{l}\text { General symptoms (QLQ- } \\
\text { C30) }\end{array}$} & $\mathrm{G} 8:</ \geq 15$ & $\begin{array}{l}23.7 / \\
11.5\end{array}$ & $\mathrm{p}=0.005$ \\
\hline & HADS: $</ \geq 15$ & $\begin{array}{l}11.8 / \\
31.6\end{array}$ & $\mathrm{p}<0.001$ \\
\hline \multirow[t]{2}{*}{$\begin{array}{l}\text { Head and neck symptoms } \\
\text { (QLQ-H\&N35) }\end{array}$} & G8: $</ \geq 15$ & $\begin{array}{l}37.4 / \\
22.4\end{array}$ & $\mathrm{p}<0.001$ \\
\hline & HADS: $</ \geq 15$ & $\begin{array}{l}24.9 / \\
43.3\end{array}$ & $\mathrm{p}<0.001$ \\
\hline \multirow[t]{3}{*}{ Mobility (QLQ-ELD14) } & Age: $</>80$ years & $\begin{array}{l}16.7 / \\
22.0\end{array}$ & $\mathrm{p}=0.004$ \\
\hline & $\begin{array}{l}\text { Alone at home: yes/ } \\
\text { no }\end{array}$ & $\begin{array}{l}33.8 / \\
17.3\end{array}$ & $\mathrm{p}=0.005$ \\
\hline & HADS: $</ \geq 15$ & $\begin{array}{l}18.8 / \\
38.9\end{array}$ & $\mathrm{p}=0.01$ \\
\hline Joint stiffness (QLQ-ELD14) & HADS: $</ \geq 15$ & $\begin{array}{l}25.2 / \\
47.9\end{array}$ & $\mathrm{p}=0.02$ \\
\hline $\begin{array}{l}\text { Worries about the future } \\
\text { (QLQ-ELD14) }\end{array}$ & HADS: $</ \geq 15$ & $\begin{array}{l}20.5 / \\
49.3\end{array}$ & $\mathrm{p}=0.001$ \\
\hline $\begin{array}{l}\text { Worries about others (QLQ- } \\
\text { ELD14) }\end{array}$ & HADS: $</ \geq 15$ & $\begin{array}{l}12.9 / \\
21.9\end{array}$ & $\mathrm{p}=0.02$ \\
\hline $\begin{array}{l}\text { Burden of illness (QLQ- } \\
\text { ELD14) }\end{array}$ & HADS: $</ \geq 15$ & $\begin{array}{l}42.6 / \\
74.0\end{array}$ & $\mathrm{p}=0.002$ \\
\hline $\begin{array}{l}\text { Family support (QLQ- } \\
\text { ELD14) }\end{array}$ & - & & \\
\hline $\begin{array}{l}\text { Maintaining purpose (QLQ- } \\
\text { ELD14) }\end{array}$ & HADS: $</ \geq 15$ & $\begin{array}{l}74.8 / \\
55.2\end{array}$ & $\mathrm{p}=0.01$ \\
\hline HADS score & - & & \\
\hline \multirow[t]{3}{*}{ DOSS score } & Site $\mathrm{T}: \mathrm{CB} / \mathrm{OP}$ & $5.5 / 4.4$ & $\mathrm{p}=0.04$ \\
\hline & G8: $</ \geq 15$ & $4.6 / 5.9$ & $\mathrm{p}<0.001$ \\
\hline & HADS: $</ \geq 15$ & $5.4 / 4.6$ & $\mathrm{p}=0.02$ \\
\hline $\begin{array}{l}\text { Number of PCI concerns } \\
\text { raised }\end{array}$ & HADS: $</ \geq 15$ & $5.2 / 9.5$ & $\mathrm{p}<0.001$ \\
\hline $\begin{array}{l}\text { Number of staff members } \\
\text { selected }\end{array}$ & - & & \\
\hline
\end{tabular}

UA: univariate analysis; MA: multivariate analysis; all variables associated with $\mathrm{p}<0.05$ on UA were included in linear regression models for MA; QoL quality of life; HADS: Hospital Anxiety and Depression Scale; DOSS: Dysphagia Outcome and Severity Scale; PCI: Patient Concerns Inventory; -: no factor identified.

\section{Physical changes}

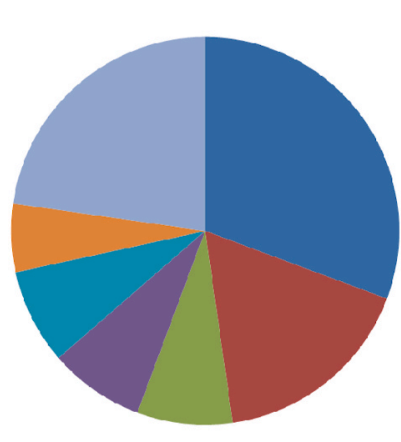

- oral diet restrictions and swallowing problems

- physical appearance

apeech problems

- fatigue

- teeth problems

salivary problems

other problems

Fig. 1. Patient responses to the open question: "What are the main physical changes impacting your daily life since OOPC surgery?"

\section{Social changes}

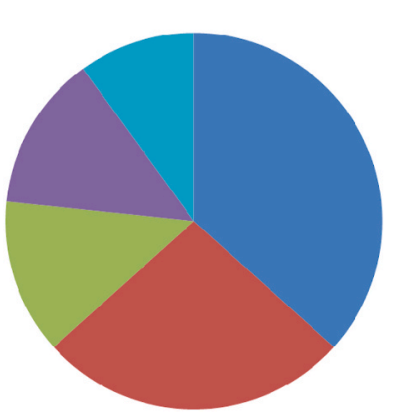

\author{
withdrawal and isolation \\ w eating out less frequently \\ - less recreation and physical \\ activities \\ - embarassed by the gaze of \\ others \\ - other problems
}

Fig. 2. Patient responses to the open question: "What are the main changes in your social life since OOPC surgery?"

frequent social changes reported by patients were: 1 ) withdrawal and isolation; 2) eating out less frequently.

\subsection{Patient concerns inventory}

The full range of concerns that patients wanted to discuss is shown in Fig. 3. The most prevalent concerns (raised by more than $25 \%$ of patients) were dry mouth ( $\mathrm{n}=29 ; 45 \%)$, chewing/eating $(\mathrm{n}=28 ; 44 \%)$, salivation ( $\mathrm{n}=25$; 39\%), mouth opening $(\mathrm{n}=25 ; 39 \%)$, swallowing ( $=22 ; 34 \%)$, dental health/teeth $(\mathrm{n}=19 ; 30 \%)$ and fear of the cancer coming back $(\mathrm{n}=18 ; 28 \%)$. The mean number of concerns raised by patients was $6.4 \pm 4.9$. A HADS score $\geq 15$ was associated with a higher number of concerns raised by patients (see Table 5). The number of concerns raised by patients was negatively correlated with the global QoL score $(r=-0.51)$ and the mean score for functioning scale $(r=$ -0.50 ), and positively correlated with the mean score for head and neck symptoms $(\mathrm{r}=0.52)$.

Overall, the members of staff that patients would like to see or be referred to are summarized in Fig. 4, with the five most common being: the surgeon $(\mathrm{n}=19 ; 30 \%)$, the dentist $(\mathrm{n}=16 ; 25 \%)$, the oral rehabilitation team $(n=15 ; 23 \%)$, the speech and swallow therapist $(n=13$; $20 \%)$ and the dietician $(n=8 ; 13 \%)$. The mean number of staff members selected by patients was $1.6 \pm 1.5$. We found no factor significantly associated with the number of staff members selected by patients and no significant correlation between this number and QoL scores.

\subsection{Swallowing and oral diet}

The mean DOSS score was $5.3 \pm 1.6$. Five (8\%) patients had a DOSS score $\leq 2$ indicating permanent enteral nutrition, and 33 patients had a 


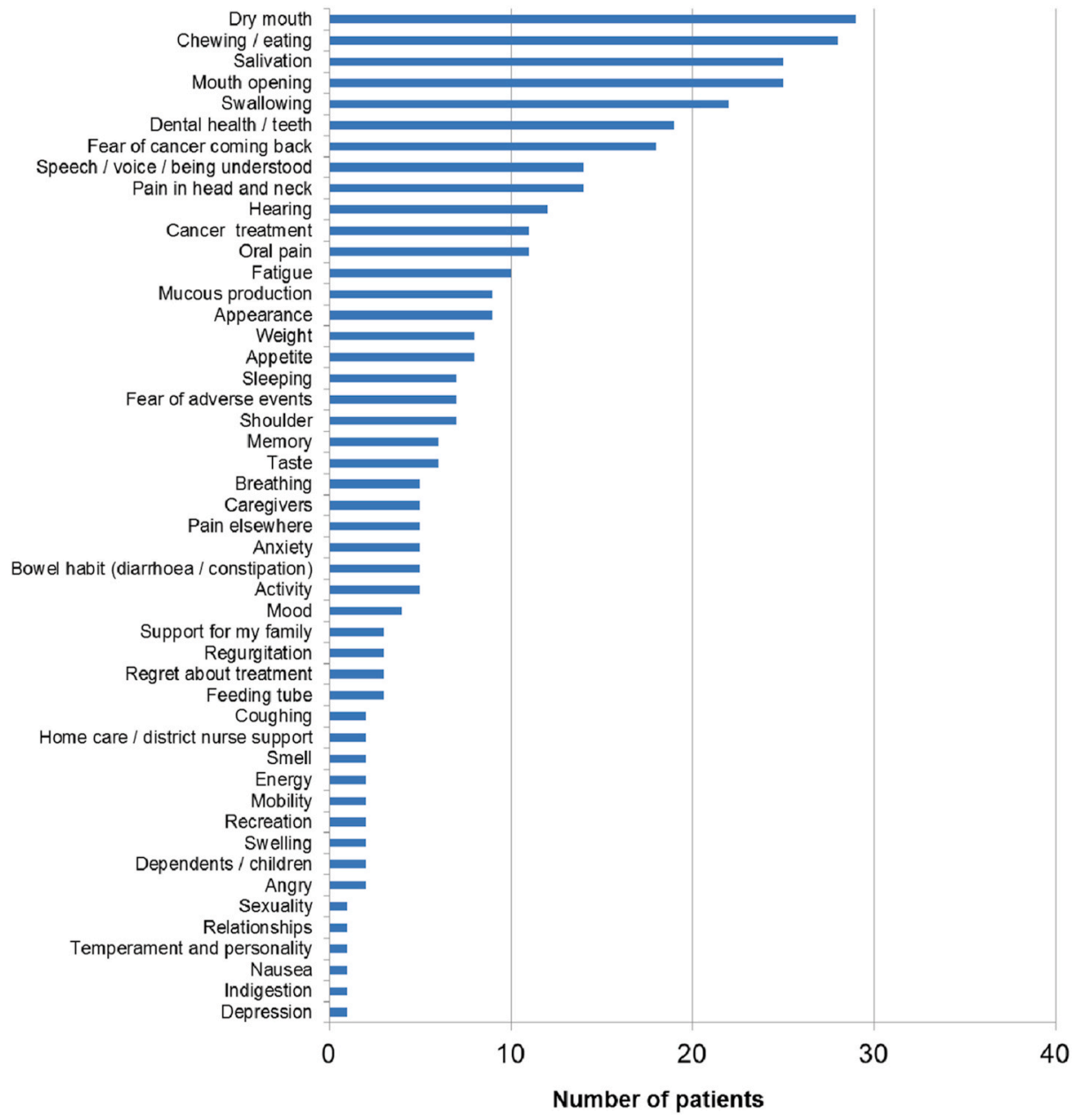

Fig. 3. Results of the Patient Concern Inventory: concerns that patients wanted to discuss with clinicians.

DOSS score $\geq 6$ representing normal/subnormal swallowing and normal diet. After uni- and multivariate analysis, tumor site (oropharynx), a G8 score $<15$ and a HADS score $\geq 15$ were significantly associated with a lower DOSS score (see Table 5).

\section{Discussion}

With the ageing of the population, more and more patients undergoing oncologic surgery and free-flap reconstruction for OOPC are aged over 70 years. While the reliability of this complex surgery in terms of postoperative complications has been confirmed in this vulnerable population, QoL and psychosocial outcomes as well as patient needs and concerns have not previously been explored [7,14]. Moreover, the clinical factors associated with QoL outcomes are still unknown in this specific population. Thus, with the GETTEC collaborative study group, we conducted an original multicentric cross-sectional study to address these important issues.

Regarding EORTC QLQ-C30 scores, QoL outcomes in the present study were satisfactory and comparable with previous studies conducted in the overall population of OOPC patients $[13,15,16]$. Global QoL and functioning scales were well-preserved, with social functioning being the most affected functioning scale, as commonly reported in the literature $[13,15-17]$. In a study on OOPC patients treated by surgery with or without RT, de Graeff et al. found remarkably similar results with a 1 -year post-treatment score of nearly $70 \%$ for global QoL and nearly $80 \%$ for all functioning scales [18]. As in other QoL studies in head and neck cancer patients, fatigue and insomnia, in the present study, were also among the most frequent persistent general symptoms $[13,15,16$,
18]. However, constipation, which was the main general symptom in our cohort of elderly patients, is not commonly described as a predominant symptom in the general population of OOPC patients and seems, therefore, to be specific to the geriatric population. Constipation is a common problem in the elderly and could be aggravated by the use of painkillers after OOPC treatment.

OOPC treatment did not seem to raise financial difficulties in the present study, probably because treatment costs are entirely supported by the French health care system and because these elderly patients suffered no loss of income since they were already retired at the time of surgery. Interestingly, in a previous study conducted by the same collaborative study group and including oropharyngeal cancer patients of all ages, Bozec et al. reported a financial difficulties score of 18.2 (4.7 in the present study) one year after therapy. This shows that, even with a high level of social protection, cancer treatment can generate major financial difficulties in young and active patients compared to elderly retired patients [15].

Reduced sexual activity and oral function-related disorders (social eating, swallowing, dental, salivary and mouth-opening problems) are the main difficulties revealed by the EORTC QLQ-H\&N35 questionnaire in our geriatric population, with reported scores that were, overall, similar to those reported by younger patients in other QoL studies [13, $15,16]$. Therefore, OOPC treatment does not appear to have a specific impact on head and neck functions in the elderly.

To our knowledge, the present study is the first study to use the EORTC QLQ-ELD14 questionnaire to explore, after OOPC primary surgical treatment, QoL domains of specific importance for elderly persons. There are few well-conducted studies assessing EORTC QLQ-ELD14 


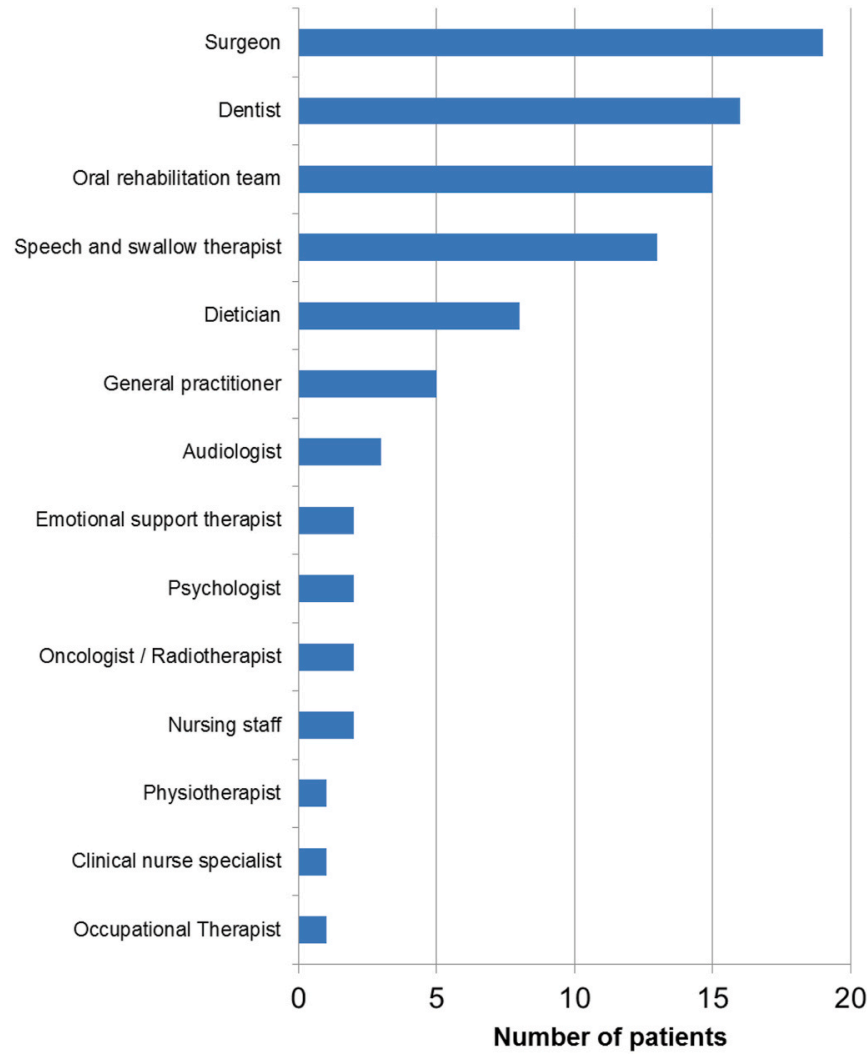

Fig. 4. Results of the Patient Concern Inventory: staff members that patients would like to consult or be referred to.

scores in elderly cancer patients. One such study was reported by Kaufmann et al. and investigated QoL in 50 patients aged over 80 years undergoing radiotherapy for different types of malignancies, including head and neck cancers [19]. Interestingly, 6 months after therapy, they showed QoL scores far worse than those observed in the present study regarding mobility, joint stiffness, worries about others, worries about the future, burden of illness and maintaining purpose. However, the population included in the Kaufman study was significantly different from the cohort in the present study, with a higher mean patient age, various types of cancer and more patients receiving palliative treatment [19]. The only comparable score between the two studies was the family support score, suggesting that, even when QoL is more severely affected by the cancer and its treatment, family support remains stable and represents a critical source of comfort for patients. Another interesting study using the EORTC QLQ-ELD4 questionnaire in elderly (>70 yrs) patients with various types of cancer was reported by Schmidt et al. [20] The study enrolled 518 patients treated with either curative or palliative intent, among whom 341 had complete data, with QoL being evaluated at any time after treatment. The authors showed remarkably similar scores to the present study except for worries about others and family support [20]. Indeed, they reported a higher level of family support and fewer worries about others in comparison with our study. We may assume that regular family support could decrease patients' anxiety and worries about their relatives.

Patient responses to the 2 open questions related to the physical changes impacting their daily lives and the main changes in their social lives were consistent with the QoL evaluation results. Indeed, the most frequent physical changes reported by patients were related to oral diet restriction and swallowing problems, thus matching the main head and neck symptoms highlighted by the EORTC QLQ-H\&N35 questionnaire. Interestingly, sexuality, which was one of the symptom scales with the highest scores, did not figure among the main physical changes reported by patients, suggesting that reduced sexual activity does not greatly affect QoL in this population. Change of physical appearance was the second most frequent physical difference impacting patients' daily life. However, there is no question in the EORTC QoL questionnaires directly addressing this important issue. This highlights the importance of combining validated QoL questionnaires with open questions when evaluating patient QoL. Not surprisingly, patient withdrawal and isolation as well as eating out less frequently were the 2 main social changes reported by the patients, a finding which corroborates the results obtained from the QoL questionnaires showing that social functioning was the most affected functioning scale and that the social eating score was one of the highest EORTC QLQ-H\&N35 scores. Changes in physical appearance would likely reduce patient confidence and social activities.

The use of the PCI in the follow-up of head and neck cancer patients was developed by Rogers and colleagues but has been little studied outside of this team $[6,10,11]$. Their work showed that completion of the PCI by patients before consultation highlights problems and concerns that doctors can target for discussion, thereby streamlining consultations and ensuring that patient needs are better met, thus delivering more effective service. In the present study, the concerns raised by patients correspond mainly to head and neck symptoms and mirror the main problems revealed by the EORTC QLQ-H\&N35 questionnaire. Interestingly, we found significant correlations between the number of concerns raised by patients and QoL scores, thus suggesting that the poorer the QoL, the greater the patients concerns. Conversely, it is also likely that attentive listening to patients and comprehensive management of their main concerns and symptoms can also improve their QoL. Since patient concerns are variable and complex, a multidisciplinary team is absolutely necessary to meet their needs and improve the care they receive. Interestingly, the PCI allowed us to identify staff members that seem essential for patients. It should be noted that the oncologis$\mathrm{t} /$ radiotherapist only ranks tenth in the list of staff members that patients would like to consult While it is not surprising that the surgeon occupies first rank on this list because of the central role played by the oncologic surgeon in the global management of head and neck cancer patients, the pressing need to see clinicians involved in dental care (dentist, oral rehabilitation team) should not go unnoticed. In this regard, it is important to note that several professionals selected by the patients correspond to specific needs of head and neck cancer patients (oral rehabilitation team, speech therapist, audiologist ...) and are not always available in comprehensive cancer centers. We believe that this type of center should adapt the composition of their multidisciplinary teams to the specific needs of the patients highlighted by this study.

The global evaluation of swallowing function using the DOSS was very encouraging since a large majority of the elderly patients included in the present study were able to recover a normal diet and a normal/ subnormal swallowing function at long term. The $8 \%$ rate of patients still dependent on enteral nutrition is satisfactory after such oncological treatment and does not seem significantly different from the results reported in the literature for younger patients $[4,15,21]$.

In the present study, $27 \%$ of patients exhibited psychological distress (global HADS score $\geq 15$ ) with $13 \%$ and $6 \%$ of patients exceeding the cut-off score of 11 for depression and anxiety, respectively. Breeman et al. reported normative data for the HADS in the UK population aged between 25 and 65 years and showed that the percentages of patients displaying a score $\geq 11$ were $7 \%$ and $16 \%$ for depression and anxiety, respectively [22]. The authors found no impact of age $>60$ years on these results and reported a mean global HADS score of 10.2 in comparison with 9.7 in our study [22]. We can conclude, therefore, that elderly OOPC patients do not display a higher global HADS score than the general population but appear to present more depressive symptoms with fewer anxiety disorders. In this regard, in an interesting study assessing psychosocial changes in 67 patients before and after cancer treatment, Gil et al. showed that anxiety was the symptom that most characterized diagnosis, whereas depression was more common after medical treatment [23]. 
One of the most interesting findings in the present study was the significant deleterious impact of a global HADS score $\geq 15$ on all QoL scores and on the number of concerns raised by patients. In a previous study on oropharyngeal cancer patients of all ages treated by radical surgery and free-flap reconstruction, we also found that the HADS global score was associated with QoL, speech and swallowing outcomes [15]. The link between psychological distress and QoL has been reported in various studies [24,25]. In this regard, in a systematic review of the literature, Dunne et al. showed that most studies found negative associations between psychological distress (depression, anxiety, distress) and QoL outcomes [26]. This is of importance because psychological distress is a modifiable factor and it can be assumed that various types of psychological intervention (appropriate psychotropic drugs, psychological/emotional support, relaxation ...) could reduce psychological distress and, consequently, improve QoL.

The second factor in the present study significantly associated with QoL and swallowing outcomes (DOSS) was the G8 score. The G8 questionnaire is easy to use and seems, therefore, to offer a useful screening tool to evaluate the risk of poor clinical and QoL outcomes in elderly patients after OOPC surgery. Interestingly, several items (appetite, weight loss, BMI, mobility) comprising this vulnerability score can receive specific interventions to reduce the frailty of elderly patients and, hence, improve their QoL. In an interesting study on 100 elderly head and neck cancer patients, Pottel et al. showed that the G8 was the screening tool of choice to identify patient vulnerability and that vulnerable patients reported lower function and higher symptom QoL scores as compared with fit patients [27]. They concluded that serial geriatric assessments identified the evolution of multidimensional health problems and QoL conditions during therapy with a potential to guide individualized supportive care [27].

The main limitations of the present study are related to its crosssectional nature which did not allow us to collect baseline data for each patient and to use these data for comparisons. Indeed, it can be assumed that some patient symptoms and invalidities were already present before treatment in this elderly population. Considering the major impact of psychological distress on patient clinical outcomes and QoL, it would have been useful to measure a preoperative HADS score. Post-therapeutic psychological distress may be due to the sequelae of cancer and its treatment and does not necessarily reflect a baseline psychological fragility. Nevertheless, preoperative data in patients faced with a diagnosis of cancer and complex treatment cannot be considered as real baseline data. However, they can be used to predict poor clinical outcomes and, thus, to improve patient selection.

\section{Conclusion}

In elderly OOPC patients treated by surgery with free-flap reconstruction, long-term QoL, general functions and patient autonomy were well-preserved, thus confirming the role of this complex surgery in a well-selected geriatric population. Main persistent symptoms were fatigue, constipation and oral function-related disorders (swallowing, dental, salivary and mouth-opening problems). More than $90 \%$ of patients recovered a full-oral diet. Patient concerns increased with the deterioration of their QoL. Psychological distress (HADS score $\geq 15$ ) and patient frailty (G8 score < 15) were associated with poor QoL and swallowing outcomes. Taken together, these results indicate that multidisciplinary management of elderly OOPC patients focused not only on cancer treatment but also involving dental rehabilitation and nutritional and psychological supportive measures could improve longterm patient QoL.

\section{Credit author statement}

Alexandre Bozec: conceptualization, methodology, investigation, resources, data curation, writing - original draft, writing - review \& editing, project administration.
Claire Majoufre: investigation, resources.

Marie De Boutray: investigation, resources.

Jocelyn Gal: methodology, software, formal analysis, resources, data curation.

Emmanuel Chamorey: methodology, software, formal analysis, resources, data curation.

Lise-Marie Roussel: investigation, resources.

Pierre Philouze: investigation, resources.

Sylvie Testelin: investigation, resources.

Marine Coninckx: investigation, resources.

Christine Bach: investigation, resources.

Philippe Schultz: investigation, resources.

Renaud Garrel: investigation, resources.

Marie-Yolande Louis: investigation, resources.

Emmanuel Babin: investigation, resources.

Alain Cosmidis: investigation, resources.

Philippe Céruse: investigation, resources.

Bertrand Baujat: investigation, resources.

Dorian Culié: investigation, resources.

Olivier Dassonville: investigation, resources, supervision.

Gilles Poissonnet: investigation, resources, supervision.

Grégoire D'Andrea: investigation, resources.

Joanne Guerlain: investigation, resources, project administration.

Sébastien Vergez: investigation, resources.

Agnès Dupret-Bories: conceptualization, methodology, investigation, resources, writing - review \& editing.

\section{Declaration of competing interest}

We have no conflict of interest to declare.

\section{References}

[1] A. Bozec, D. Culie, G. Poissonnet, O. Dassonville, Current role of primary surgical treatment in patients with head and neck squamous cell carcinoma, Curr. Opin. Oncol. 31 (2019) 138-145.

[2] A. Bozec, G. Poissonnet, E. Chamorey, et al., Free-flap head and neck reconstruction and quality of life: a 2-year prospective study, Laryngoscope 118 (2008) 874-880.

[3] O. Camuzard, O. Dassonville, M. Ettaiche, et al., Primary radical ablative surgery and fibula free-flap reconstruction for T4 oral cavity squamous cell carcinoma with mandibular invasion: oncologic and functional results and their predictive factors, Eur. Arch. Oto-Rhino-Laryngol. 274 (2017) 441-449.

[4] C.S. Pierre, O. Dassonville, E. Chamorey, et al., Long-term functional outcomes and quality of life after oncologic surgery and microvascular reconstruction in patients with oral or oropharyngeal cancer, Acta Otolaryngol. 134 (2014) 1086-1093.

[5] K. Ligier, A. Belot, G. Launoy, et al., Descriptive epidemiology of upper aerodigestive tract cancers in France: incidence over 1980-2005 and projection to 2010, Oral Oncol. 47 (2011) 302-307.

[6] S.N. Rogers, R.A. Audisio, D. Lowe, Do the elderly raise different issues when using the Patient Concerns Inventory in routine head and neck cancer follow-up clinics? Eur. J. Canc. Care (Engl.) 24 (2015) 189-197.

[7] C.S. Goh, Y.O. Kok, C.P. Yong, et al., Outcome predictors in elderly head and neck free flap reconstruction: a retrospective study and systematic review of the current evidence, J. Plast. Reconstr. Aesthetic Surg. 71 (2018) 719-728.

[8] C.A. Bellera, M. Rainfray, S. Mathoulin-Pelissier, et al., Screening older cancer patients: first evaluation of the G-8 geriatric screening tool, Ann. Oncol. 23 (2012) 2166-2172.

[9] A. Hinz, P.Y. Herzberg, F. Lordick, et al., Age and gender differences in anxiety and depression in cancer patients compared with the general population, Eur. J. Canc. Care (Engl.) 28 (2019), e13129.

[10] S.N. Rogers, D. Lowe, An evaluation of the head and neck cancer patient concerns inventory across the merseyside and cheshire network, Br. J. Oral Maxillofac. Surg. 52 (2014) 615-623.

[11] S.N. Rogers, D. Lowe, A. Kanatas, Suitability of the Patient Concerns Inventory as a holistic screening tool in routine head and neck cancer follow-up clinics, Br. J. Oral Maxillofac. Surg. 54 (2016) 415-421.

[12] K.H. O'Neil, M. Purdy, J. Falk, L. Gallo, The dysphagia outcome and severity scale, Dysphagia 14 (1999) 139-145.

[13] C.S. Pierre, O. Dassonville, E. Chamorey, et al., Long-term quality of life and its predictive factors after oncologic surgery and microvascular reconstruction in patients with oral or oropharyngeal cancer, Eur. Arch. Oto-Rhino-Laryngol. 271 (2014) 801-807.

[14] E.E. Nao, O. Dassonville, E. Chamorey, et al., Head and neck free-flap reconstruction in the elderly, Eur. Ann. Otorhinolaryngol. Head Neck Dis. 128 (2011) 47-51. 
[15] A. Bozec, P. Demez, J. Gal, et al., Long-term quality of life and psycho-social outcomes after oropharyngeal cancer surgery and radial forearm free-flap reconstruction: a GETTEC prospective multicentric study, Surg. Oncol. 27 (2018) 23-30.

[16] S.T. Becker, M. Menzebach, T. Kuchler, et al., Quality of life in oral cancer patients-effects of mandible resection and socio-cultural aspects, J. CranioMaxillo-Fac. Surg. 40 (2012) 24-27.

[17] Li W, Yang Y, Xu Z et al.: Assessment of quality of life of patients with oral cavity cancer who have had defects reconstructed with free anterolateral thigh perforator flaps. Br. J. Oral Maxillofac. Surg. 51:497-501.

[18] A. de Graeff, J.R. de Leeuw, W.J. Ros, et al., Sociodemographic factors and quality of life as prognostic indicators in head and neck cancer, Eur. J. Canc. 37 (2001) 332-339.

[19] A. Kaufmann, H. Schmidt, C. Ostheimer, et al., Quality of life in very elderly radiotherapy patients: a prospective pilot study using the EORTC QLQ-ELD14 module, Support. Care Canc. 23 (2015) 1883-1892.

[20] H. Schmidt, T. Nordhausen, S. Boese, et al., Factors influencing global health related quality of life in elderly cancer patients: results of a secondary data analysis, Geriatrics (Basel) 3 (2018).
[21] S.N. Rogers, R. Thomson, P. O'Toole, D. Lowe, Patients experience with long-term percutaneous endoscopic gastrostomy feeding following primary surgery for oral and oropharyngeal cancer, Oral Oncol. 43 (2007) 499-507.

[22] S. Breeman, S. Cotton, S. Fielding, G.T. Jones, Normative data for the hospital anxiety and depression scale, Qual. Life Res. 24 (2015) 391-398.

[23] F. Gil, G. Costa, I. Hilker, L. Benito, First anxiety, afterwards depression: psychological distress in cancer patients at diagnosis and after medical treatment, Stress Health 28 (2012) 362-367.

[24] A.K. Aarstad, E. Beisland, A.A. Osthus, H.J. Aarstad, Distress, quality of life, neuroticism and psychological coping are related in head and neck cancer patients during follow-up, Acta Oncol. 50 (2011) 390-398.

[25] C.D. Llewellyn, M. McGurk, J. Weinman, Head and neck cancer: to what extent can psychological factors explain differences between health-related quality of life and individual quality of life? Br. J. Oral Maxillofac. Surg. 44 (2006) 351-357.

[26] S. Dunne, O. Mooney, L. Coffey, et al., Psychological variables associated with quality of life following primary treatment for head and neck cancer: a systematic review of the literature from 2004 to 2015, Psycho Oncol. 26 (2017) 149-160.

[27] L. Pottel, M. Lycke, T. Boterberg, et al., Serial comprehensive geriatric assessment in elderly head and neck cancer patients undergoing curative radiotherapy identifies evolution of multidimensional health problems and is indicative of quality of life, Eur. J. Canc. Care (Engl.) 23 (2014) 401-412. 